\title{
PERANAN TENAGA PENGAJAR (DOSEN) PROFESIONAL DALAM PEMBENTUKAN KARAKTER MAHASISWA UNTUK PENINGKATAN KUALITAS PEMBELAJARAN DI PROGRAM STUDI PENDIDIKAN LUAR SEKOLAH
}

\author{
Yasaratodo Wau, Anifah dan Vidya Amalia Zati*) \\ Surel: yasaratodo@gmail.com
}

\begin{abstract}
The purpose of research here is To be able to describe the role of professional teaching staff (Lecturer) in the formation of student characters. To be able to describe the role of professional faculty (Lecturer) in improving the quality of learning, to see the role of professional teaching staff (Lecturer) and the formation of student character in improving the quality of learning in the Out of School education program. The type of this research is quantitative descriptive research. This research is a research using regression analysis research two predictor. Data analysis technique used in this research In this study used the data validity and data reliability test method in viewing the role of professional lecturers in the formation of student character to improve the quality of learning through the initial test and final test. Data analysis technique in the form of quantitative descriptive method then used frequency table with product moment correlation formula.For result of this research is There is existence of reabel data from 15 items to 30 respondents with result $80,1 \%$ between role of lecturers (lecturer) professional in forming student character for improvement of learning quality. To see hypothesis test from X1 data with $Y$ then used correlation test and regression 2 person variable. The result of $X 1$ data to $Y$ has a significant role between professional teaching staff with learning quality with correlation data $X 1=5,75 \%$ to data $Y=$ $0,01 \%$. Correlation data X2 to $Y$ has significant and valid data between variables $X 2$ and $Y$. The data has a role of $7.35 \%$ formation of student characters on the quality of learning $0.1 \%$. The data of linear regression analysis 2 predictors between $X 1, X 2$ and $Y$. The data result is $0.737 \%$ with $0.543 \%$. Where has a significant and valid role between professional faculty in the formation of student characters to improve the quality of learning diprodi outside education faculty of science faculty of state universities university.
\end{abstract}

Kata Kunci: Guru Profesional, Pembangunan Karakter, Kualitas Pembelajaran

\section{PENDAHULUAN}

Peranan dosen dalam mentransformasikan ilmu pengetahuan dan teknologi, dimana saat ini menurut analisa refleksi para ahli, fungsi ilmu pengetahuan dan teknologi bukan lagi merupakan sarana dalam membantu manusia untuk mencapai tujuan hidup, tetapi ilmu pengetahuan dan teknologi dapat menciptakan tujuan manusia untuk hidup. Melalui kegiatan

\footnotetext{
*) Dr. Yasaratodo Wau, M.Pd: Dosen Jurusan PLS FIP UNIMED

Anifah, S.Sos., M.Pd: Dosen Jurusan PLS FIP UNIMED

Vidya Amalia Zati, S.S., M.Hum: Dosen Jurusan PLS FIP UNIMED
} 
pembelajaran dosen berperan serta dalam mencerahkan dan mentransformasikan ilmu dan teknologinya kepada mahasiswa mengenai berbagai hal yang terjadi dalam pengembangan ilmu pengetahuan dan teknologi.

Pembelajaran bukan hanya sekedar mengenalkan kepada para mahasiswa semata faktanya saja tetapi konsep, prinsip, dan prosedurnya juga wajib mahasiswa hendaknya diarahkan untuk bisa sampai pada tahapan bagaimana mampu menganalisa, mensintesis, mengevaluasi, dan merefleksikan berbagai persoalan yang relevan. Tahapan inilah mahasiswa dapat berkarya dengan memberikan kontribusi terhadap dunia pendidikan, seperti melakukan pembuatan karya ilmiah dan penelitian secara sederhana. Perubahan seperti itu memberikan dampak besar bagi mahasiswa dan dunia pendidikan bahkan menjadikan suatu pengalaman akademis mahasiswa yang dilakukan ketika dimasa proses pembelajaran di kampus.

Peranan sebagai pengembang (developer) merupakan peranan yang dilakukan dalam Tridharma Perguruan Tinggi yaitu melalui kegiatan penelitian. Kegiatan penelitian dapat mengembaangkan ilmu pengetahuan, teknologi, dan seni, yang hasilnya dapat dimanfaatkan sebesar-besarnya untuk kesejahteraan masyarakat, melalui penelitian dosen dapat mengembangkan peranan diri menjadi manusia yang berkualitas antara lain indikator yang menjadikan dosen sebagai peneliti yang baik, yaitu : (a). Dosen dapat mempublikasikan penelitian secara luas misalnya melalui jurnal, buku, media online ataupun media cetak; (b). Dosen mampu berkompetisi dalam membuat proposal penelitian; (c). Dosen mampu membuat penelitian berlandaskan etika penelitian; (d). Dosen mampu membuat terobosan dan memunculkan gagasan baru melalui kajian terdahulu; dan (e). Dosen mampu menumbuhkan budaya penelitian dilingkungan perguruan tinggi.

Menyebarluaskan ilmu pengetahuan, teknologi dan seni dilakukan melalui fungsi pengabdian kepada masyarakat. Pengabdian dengan maksud mengangkat derajat hidup dan berkhidmat kepada masyarakat. Pengabdian dapat berupa pelayanan terhadap masyarakat khususnya masyarakat sekolah/lembaga pendidikan, dosen dengan ilmunya memberikan karya ilmiah sebagai penguatan informasi terhadap dunia pendidikan. Pengabdian juga dapat dilakukan dengan bentuk program kerja bersama instansi bahkan pengabdian masyarakat melalui kerjasama dengan yayasan sosial dalam bentuk pemberdayaan/peguatan masyarakat. Bersama tugas dan tanggung jawab dosen dalam partisipasi membangun dunia pendidikan, disinilah karakter unggul terbentuk melalui penerapan 
langsung di perguruan tinggi bahkan menjadikan pembentukan karakter bagi mahasiswa melalui ilmu pengetahuan dan teknologi yang menjadi modal besar bangsa dalam mencerdaskan kehidupan. Selaras dengan tujuan yang mendasar dalam pandangan cita-cita bangsa Indonesia.

\section{Perguruan Tinggi (PT)} sebagai lembaga penyelenggara pendidikan memiliki peranan yang sangat besar dalam kerangka pembangunan nasional. Ada dua tugas pokok yang diemban oleh Perguruan Tinggi yaitu pertama, mendidik putra-putri bangsa agar menguasai IPTEKS, dan kedua, melokomotifi pembangunan nasional dan daerah termasuk mempersiapkan calon-calon pemimpin bangsa yang bermoral tinggi serta berbudaya demokratis (Sofian Effendi, 2003). Perguruan Tinggi berfungsi sebagai produsen utama sumber daya manusia bagi kebutuhan masyarakat dan untuk dapat meningkatkan, menyebarluaskan, dan mengembangkan IPTEKS (Ilmu Pengetahuan Teknologi dan Sains) itu sendiri.

Dalam menjalankan peranannya, Perguruan Tinggi menghadapi tantangan yang besar dalam era globalisasi. Globalisasi yang dicirikan oleh banjirnya arus informasi dan hilangnya sekat-sekat batas antarnegara sebagai akibat perkembangan dan kemajuan teknologi komunikasi dan informasi harus direspon secara akurat dan bijak. Dengan demikian, eksistensi Perguruan Tinggi di masyarakat tetap bisa dipertahankan. Perguruan tinggi mengemban tanggungjawab dan kewajiban yang besar, khususnya dalam melahirkan sumberdaya intelektual, yang diharapkan nantinya bisa memberikan kontribusi bagi peningkatan kualitas sumber daya manusia (SDM) bangsa ini. Perguruan Tinggi juga harus mampu mengkonstruktivitaskan institusinya secara moral dan manajerial agar dapat survive dan mampu menyediakan semua proses intelektual produk yang dihasilkannya kepada masyarakat secara sistematis, berkelanjutan dan sesuai dengan tuntutan dan kebutuhan masyarakat tentang harapan dan cita-citanya mendapatkan manfaat belajar di perguruan tinggi, sehingga dari harapan inilah menjadikan peran perguruan tinggi sebagai menara gading dan corong intelektual ditengah-tengah masyarakat. Semenjak pemerintah memberlakukan pendidikan karakter secara nasional di semua jenjang pendidikan (Kompas, 13/7/2011), pendidikan karakter menjadi isu hangat dibidang pendidikan, tidak terkecuali di Perguruan Tinggi. Beberapa forum ilmiah, seminar dan diskusi melibatkan pakar berbagai disiplin ilmu, khususnya pendidikan. Pada kegiatan itu membahas tentang karakter secara mendalam hingga menjadi fokus topik dan tidak melebar kemana-mana. 
Menurut Ki Hajar Dewantara, karakter dipandang sebagai watak atau budi pekerti, dengan kata lain bersatunya gerak pikiran, perasaan dan kehendak atau kemauan yang kemudian menimbulkan tenaga. Dengan adanya budi pekerti manusia akan menjadi pribadi yang merdeka sekaligus berkepribadian dan dapat mengendalikan diri sendiri atau mandiri. Pendidikan yang baik menurut Ki Hajar Dewantara yaitu mampu mengalahkan dasar-dasar jiwa manusia yang jahat, menutupi, bahkan mengurangi sifat-sifat yang negatif. Pendidikan dikatakan optimal jika sifat luhur lebih menonjol dalam diri daripada sifatsifat negatif. Manusia berkarakter inilah yang menurut $\mathrm{Ki}$ Hajar Dewantara sebagai sosok beradab, sosok menjadi ancangan sejati pendidikan. Sehingga keberhasilan pendidikan sejati adalah menghasilkan manusia beradab, bukan yang cerdas secara kognitif dan psikomotorik tetapi miskin karakter dan budi pekerti luhur.

Pendidikan karakter menjadi tuntutan para pengajar khususnya bagi dosen sudah selayaknya dominan dimiliki dan tampak menonjol dari pribadi seorang dosen. Pendidikan karakter pula yang menjadikan budi pekerti terhadap apa dan siapa yang akan dibimbing untuk menghasilkan pribadi berbudi pekerti plus, yaitu pendidikan yang melibatkan aspek pengetahuan (cognitive), perasaan (feeling), dan tindakan (action). Ketika ketiga aspek diterapkan secara sistematis dan berkelanjutan, maka peserta didik menjadi cerdas emosinya. Kecerdasan emosi ini menjadi bekal guna mempersiapkan anak menyongsong masa depan, karena akan lebih mudah dan berhasil menghadapi segala macam tantangan kehidupan, termasuk tantangan untuk berhasil secara akademik.

$$
\text { Pendidikan karakter }
$$

merupakan usaha yang disengaja untuk mengembangkan karakter yang baik berdasarkan nilai-nilai inti yang baik untuk individu dan baik untuk masyarakat. Salah satu lembaga yang dapat berperan dalam pendidikan karakter adalah perguruan tinggi. Dengan demikian, dalam lingkungan perguruan tinggi tersebut tersedia suatu lingkungan moral (moral environtment) yang menekankan nilai-nilai yang baik dan menjaganya dalam kesadaran setiap orang. Sebuah lingkungan yang dapat mengubah nilai menjadi sebuah kebaikan dan mengembangkan kesadaran intelektual menjadi kebiasaan personal dalam pikiran, perasaan dan tindakan. Selain memiliki karakter ideal yang diuraikan sebelumnya karakter juga menjadi tantangan yang begitu berat dan komplek bagi pendidik, juga hasil dari karakter yang diberikan juga memiliki soft skill atau kecakapan hidup. Dengan kata lain soft skill sebagai bagian karakter mahasiswa dan memiliki peran yang amat penting. Bahkan umumnya praktik pendidikan yang dilakukan 
cenderung berorientasi pada pendidikan berbasis hard skill (keterampilan teknis) yang lebih bersifat mengembangkan Intelligence Quotient (IQ), namun kurang mengembangkan kemampuan soft skill yang tertuang dalam Emosional Quotient (EQ), dan Spiritual Qoutient (SQ). Kritikan dalam pendidikan yang berbasis hard skill, saat ini sudah mulai bergeser.

Saat ini mulai ditekankan pembelajaran yang berbasis soft skill (interaksi sosial), karena dalam pembentukan karakter generasi bangsa harus mampu bersaing, beretika, bermoral, sopan santun, dan berinteraksi dengan masyarakat. Pendidikan soft skill bertumpu pada pembinaan mentalitas agar anak bangsa dapat menyesuaikan diri dengan realitas kehidupan. Singkatnya saat ini dalam dunia pendidikan telah timbul kesadaran bahwa kesuksesan seseorang tidak ditentukan semata-mata oleh pengetahuan dan keterampilan teknis (hard skill) saja, tetapi juga kerampilan mengelola diri dan orang lain. Akan tetapi, tidak semua mahasiswa dan dosen sadar akan peranannya. Berdasarkan pemikiranpemikiran di atas maka penulis tertarik untuk mengadakan penelitian tentang "Peranan Tenaga Pengajar (Dosen) Profesional Dalam Pembentukan Karakter Mahasiswa Untuk Peningkatan Kualitas Pembelajaran di Program Studi Pendidikan Luar Sekolah".

\section{Rumusan Masalah}

Berdasarkan masalah umum tersebut, maka dapat dirumuskan permasalahan penelitian sebagai berikut :

1. Bagaimana peranan Tenaga Pengajar Profesional (Dosen) dalam pembentukan karakter mahasiswa.

2. Bagaimana peranan Tenaga Pengajar Profesional (Dosen) dalam peningkatan kualitas pembelajaram

3. Apakah ada peranan tenaga pengajar profesional (Dosen) dengan mahasiswa dalam pembentukan karakter untuk peningkatan kualitas pembelajaran di program studi Pendidikan Luar Sekolah.

\section{Tujuan Penelitian}

Berdasarkan permasalahan di atas maka yang menjadi tujuan penelitian ini adalah sebagai berikut :

1. Untuk dapat mendeskripsikan peranan tenaga pengajar profesional (Dosen) dalam pembentukan karakter mahasiswa.

2. Untuk dapat mendeskripsikan peranan tenaga pengajar profesional (Dosen) dalam peningkatan kualitas pembelajaran.

3. Untuk melihat peranan tenaga pengajar profesional (Dosen) dan pembentukan karakter mahasiswa dalam peningkatan kualitas pembelajaran di program studi Pendidikan Luar Sekolah.

\subsection{Manfaat Penelitian}

Penelitian ini diharapkan dapat memberikan manfaat yang khusus bagi pendidik dan tenaga 
kependidikan di program studi pendidikan luar sekolah tentang pembentukan karakter mahasiswa untuk peningkatan kualitas pembelajaran. Secara rinci manfaat penelitian ini sebagai berikut :

1. Sebagai bahan masukan bagi pendidik dan tenaga kependidikan pendidikan luar sekolah tentang pembentukan karakter mahasiswa.

2. Sebagai bahan masukan bagi pendidik dan tenaga kependidikan pendidikan luar sekolah tentang pembentukan karakter mahasiswa dalam peningkatan kualitas pembelajaran .

3. Sebagai bahan masukan dan rangsangan bagi pendidik dan tenaga kependidikan untuk penelitian selanjutnya mengenai pembentukan karakter mahasiswa untuk peningkatan kualitas pembelajaran.

\section{METODE PENELITIAN}

\section{Rancangan Penelitian}

Adapun jenis penelitian yang digunakan dalam penelitian ini adalah penelitian deskriptif kuantitatif. Yang mana penelitian deskriptif kuantitatif merupakan penelitian yang penekanannya pada angka-angka dari perhitungan untuk mencari peranan tenaga pengajar profesional (Dosen) dalam pembentukan karakter mahasiswa untuk peningkatan kualitas pembelajaran di program studi pendidikan luar sekolah. Penelitian ini merupakan penelitian yang memiliki penilaian pada awal proses pembelajaran (test awal) yang diberikan oleh tenaga pengajar (Dosen) profesional dalam pembentukan karakter mahasiswa dan penilaian akhir proses pembelajaran (test akhir) yang diberikan oleh tenaga pengajar (Dosen) profesional dalam pembentukan karakter mahasiswa untuk peningkatan kualitas pembelajaran di Prodi Pendidikan Luar Sekolah.

\section{Lokasi dan Waktu Penelitian}

Penelitian ini dilakukan mulai dari bulan April sampai dengan November 2016 di Program Studi Pendidikan Luar Sekolah Fakultas Ilmu Pendidikan Unimed Semester Ganjil 2016/2017. Pelaksanaan berlangsung selama 8 kali pertemuan (8 x 50 menit) untuk masing-masing kelas sampel.

\section{Populasi Penelitian}

Populasi dalam penelitian ini yaitu seluruh mahasiswa Jurusan PLS NIM 2015. Sampel diambil dengan teknik pengambilan sampel acak setelah diberikan perlakuan di masing-masing kelas. 


\section{TABEL 1 : DATA MAHASISWA PROGRAM STUDI PENDIDIKAN LUAR SEKOLAH SEMESTER GANJIL 2016/2017}

\begin{tabular}{|c|c|c|c|c|c|c|c|c|c|c|c|c|c|}
\hline \multirow{3}{*}{ STAMBUK } & \multicolumn{6}{|c|}{ REGULER } & \multicolumn{4}{|c|}{ EKSTENSI } & \multirow{2}{*}{\multicolumn{2}{|c|}{$\begin{array}{c}\text { JUMLAH } \\
\text { REG/EKS }\end{array}$}} & \multirow{3}{*}{$\begin{array}{c}\text { JUMLAH } \\
\text { TOTAL }\end{array}$} \\
\hline & \multicolumn{2}{|c|}{$\begin{array}{c}\text { BIDIK } \\
\text { MISI/PMP }\end{array}$} & \multicolumn{2}{|c|}{ SNMPTN } & \multicolumn{2}{|c|}{ JUMLAH } & \multicolumn{2}{|c|}{ EKSTENSI } & \multicolumn{2}{|c|}{ JUMLAH } & & & \\
\hline & $\mathbf{L}$ & $\mathbf{P}$ & $\mathbf{L}$ & $\mathbf{P}$ & $\mathbf{L}$ & $\mathbf{P}$ & $\mathbf{L}$ & $\mathbf{P}$ & $\mathbf{L}$ & $\mathbf{P}$ & $\mathbf{L}$ & $\mathbf{P}$ & \\
\hline 2009 & 0 & 0 & 0 & 0 & 0 & 0 & 0 & 0 & 0 & 0 & 0 & 0 & 0 \\
\hline 2010 & 0 & 0 & 1 & 1 & 1 & 1 & 1 & 0 & 1 & 0 & 2 & 1 & 3 \\
\hline 2011 & 1 & 0 & 2 & 7 & 3 & 7 & 2 & 5 & 2 & 5 & 5 & 12 & 17 \\
\hline 2012 & 0 & 0 & 5 & 12 & 5 & 12 & 3 & 16 & 3 & 16 & 8 & 28 & 36 \\
\hline 2013 & 9 & 21 & 8 & 13 & 18 & 34 & 5 & 21 & 5 & 21 & 23 & 55 & 78 \\
\hline 2014 & 9 & 30 & 8 & 12 & 17 & 42 & 2 & 9 & 2 & 9 & 19 & 51 & 70 \\
\hline 2015 & 5 & 27 & 7 & 14 & 12 & 41 & 6 & 14 & 6 & 14 & 18 & 55 & 73 \\
\hline 2016 & 6 & 16 & 14 & 35 & 20 & 51 & 2 & 17 & 2 & 17 & 22 & 68 & 90 \\
\hline & & & & JUN & AH & LUU & $\mathrm{UHN}$ & & & & & & 367 \\
\hline
\end{tabular}

\section{Teknik Pengumpulan Data}

Data dikumpulkan melalui metode dokumentasi, test (angket) dan observasi. Metode dokumentasi digunakan untuk memperoleh data mahasiswa berupa daftar nama mahasiswa dan jumlah mahasiswa. Sedangkan metode yang digunakan metode observasi di dalam memperoleh data pembentukan karakter mahasiswa.

\section{Teknik Analisis Data}

Dalam penelitian ini menggunakan metode uji validitas data dan reabilitas data di dalam melihat peranan tenaga pengajar (dosen) professional dalam pembentukan karakter mahasiswa untuk peningkatan kualitas pembelajaran melalui test awal dan test akhir. Adapun yang menjadi Prosedur dalam Pelaksanaan penelitian untuk mengetahui peranan tenaga pengajar (Dosen) Profesional dalam pembentukan karakter mahasiswa untuk peningkatan kualitas pembelajaran di Program Studi Pendidikan Luar Sekolah dilakukan melalui prosedur sebagai berikut:

1. Memilih obyek penelitian, yaitu mahasiswa yang dalam proses pembelajaran pada masing-masing dosen PLS untuk semester ganjil 2015/2016 secara acak.

2. Melakukan observasi awal dalam proses pembelajaran yang dilakukan oleh tenaga pengajar (dosen) profesional dalam pembentukan karakter mahasiswa 
untuk peningkatan kualitas pembelajaran di dalam kelas.

3. Melakukan test awal (angket) kepada mahasiswa di prodi PLS FIP Unimed dan menghitung nilai rata-rata hasil test awal (angket) masing-masing kelompok dalam proses pembelajaran.

4. Melaksanakan pembelajaran sesuai dengan perlakuan yang telah ditetapkan.

5. Melakukan test akhir (angket) kepada mahasiswa di prodi PLSFIP Unimed terhadap kedua kelompok dalam proses pembelajaran yang diberikan masing-masing dosen selama satu semester di Prodi PLS.

6. Menghitung nilai rata-rata hasil test akhir (angket) masing-masing kelompok dalam proses pembelajaran yang diberikan masing-masing dosen selama satu semester di Prodi PLS.

Pengujian hipotesis penelitian dilakukan dengan menggunakan korelasi, regresi dan annova untuk melihat seberapa peranan tenaga pengajar (dosen) professional dalam pembentukan karakter mahasiswa untuk peningkatan kualitas pembelajaran di prodi PLS-FIP Unimed.

\section{HASIL DAN PEMBAHASAN Deskripsi Data}

Aktivitas pertama yang dilakukan dalam penelitian deskriptif kuantitatif ini yaitu memilih dan menentukan populasi dan sampel penelitian. Kemudian dari populasi penelitian ditentukan sampel penelitian yaitu mahasiswa Jurusan PLS NIM 2015 Kelas Reguler A dan B. Pengelompokkan sampel penelitian, dilakukan berdasarkan kelas. Kelas Reguler A dengan jumlah siswa sebanyak 30 orang mahasiswa ditetapkan sebagai kelompok perlakuan; sementara Kelas Reguler B dengan 30 orang mahasiswa. Kemudian, kedua kelompok kelas ini diberikan penjelasan tentang peningkatan kualitas pembelajaran dimasingmasing mata kuliah yang diberikan oleh masing-masing dosen sehingga dosen tersebut dapat membentuk karakter mahasiswa prodi PLS dalam proses pembelajaran. Proses pembelajaran dengan menggunakan topik tersebut dimulai dengan pemberian test awal kepada mahasiswa kemudian diakhiri dengan pemberian test akhir kepada mahasiswa.

\section{Melaksanaan Observasi Awal dan Test Awal}

Peneliti melakukan pelaksanaan observasi awal/melihat di luar kelas di program studi pendidikan luar sekolah dalam proses pembelajaran yang dilakukan oleh para pengajar (dosen) profesional kepada mahasiswa-mahasiswi di setiap mata pelajaran kemudian peneliti di bantu oleh para mahasiswa yang ditunjuk untuk dapat menyebarkan angket awal dalam penelitian yang dilakukan terhadap kedua kelompok dengan jenis soal 
yang sama. Soal test awal ini berbentuk tes tertulis pilihan ganda dengan_nstrument. Jumlah soal sebanyak 25 butir dengan durasi waktu mengerjakan 50 menit (1 SKS). Bobot untuk setiap butir soal berbeda-beda butir soalnya yaitu bobot butir pertama berjumlah 10 (sepuluh)butir soal, butir yang kedua berjumlah 15 (lima belas). Jadi, nilai maksimum yang didapatkan mahasiswa adalah 100. Kemudian hasil test awal tersebut diperiksa dan berdasarkan hasil pemeriksaan tersebut dicari: nilai terendah, nilai tertinggi, dan nilai rata-rata.

\section{Pelaksanaan Pembelajaran}

Setelah dilakukan test awal, kemudian dilakukan proses pembelajaran dengan beberapa materi pembelajaran yang diberikan masing-masing dosen di prodi pendidikan luar sekolah. Durasi waktu pembelajaran untuk kedua kelompok sama, yaitu 8 kali 50 menit untuk materi pembelajaran yang diberikan oleh masing-masing dosen sehingga nantinya dapat terlihat peranan tenaga pengajar (dosen) dan pembentukan karakter mahasiswa dalam peningkatan kualitas pembelajaran.

\subsubsection{Pelaksanaan Test Akhir}

Sama halnya seperti pada test awal, test akhir pada penelitian ini juga dilakukan terhadap dua kelompok perlakuan dengan materi, jumlah, dan opsi pertanyaan yang sama. Jumlah soal sebanyak 25 butir dengan durasi waktu mengerjakan 50 menit (1 SKS). Bobot untuk setiap butir soal berbeda-beda butir soalnya yaitu bobot butir pertama berjumlah 10 (sepuluh) butir soal, butir yang kedua berjumlah 15 (lima belas). Jadi, nilai maksimum yang didapatkan mahasiswa adalah 100. Kemudian hasil test awal tersebut diperiksa dan berdasarkan hasil pemeriksaan tersebut dicari: nilai terendah, nilai tertinggi, dan nilai rata-rata.

\section{Analisis Data}

\section{Analisis Hasil Observasi dan Test} Awal

Test awal dilakukan untuk mengetahui kompetensi awal yang dimiliki oleh para tenaga pengajar (dosen) profesional dalam proses pembelajaran kepada para mahasiswa-mahasiswi di prodi pendidikan luar sekolah yang berkaitan dengan penelitian peranan tenaga pengajar (dosen) profesional dalam pembentukan karakter mahasiswa untuk peningkatan kualitas pembelajaran di Program Studi Pendidikan Luar Sekolah. Selain itu, test awal yang dilakukan peneliti untuk melihat apakah memiliki peranan tenaga pengajar (dosen) dalam pembentukan karakter mahasiswa untuk peningkatan kualitas pembelajaran di masingmasing mata kuliah yang diberikan oleh dosen yang bersangkutan. 
Tabel 4 :Data Korelasi Product Moment X1, X2 dan Y

\begin{tabular}{|c|c|c|c|c|c|c|}
\hline \multirow{2}{*}{ Subjek } & \multicolumn{6}{|c|}{ Butir Item } \\
\hline & X1 & $\mathrm{X} 2$ & $Y$ & $\mathbf{X 1}^{2}$ & $\mathbf{X 2 ^ { 2 }}$ & $\mathbf{Y}^{2}$ \\
\hline 1 & 63 & 65 & 124 & 3969 & 4225 & 15376 \\
\hline 2 & 60 & 65 & 119 & 3600 & 4225 & 14161 \\
\hline 3 & 62 & 70 & 118 & 3844 & 4900 & 13924 \\
\hline 4 & 65 & 70 & 124 & 4225 & 4900 & 15376 \\
\hline 5 & 64 & 70 & 119 & 4096 & 4900 & 14161 \\
\hline 6 & 62 & 75 & 118 & 3844 & 5625 & 13924 \\
\hline 7 & 56 & 75 & 124 & 3136 & 5625 & 15376 \\
\hline 8 & 56 & 65 & 119 & 3136 & 4225 & 14161 \\
\hline 9 & 57 & 65 & 118 & 3249 & 4225 & 13924 \\
\hline 10 & 61 & 60 & 124 & 3721 & 3600 & 15376 \\
\hline 11 & 60 & 65 & 119 & 3600 & 4225 & 14161 \\
\hline 12 & 62 & 65 & 118 & 3844 & 4225 & 13924 \\
\hline 13 & 57 & 70 & 124 & 3249 & 4900 & 15376 \\
\hline 14 & 57 & 70 & 119 & 3249 & 4900 & 14161 \\
\hline 15 & 62 & 65 & 118 & 3844 & 4225 & 13924 \\
\hline 16 & 60 & 65 & 124 & 3600 & 4225 & 15376 \\
\hline 17 & 60 & 70 & 119 & 3600 & 4900 & 14161 \\
\hline 18 & 56 & 65 & 118 & 3136 & 4225 & 13924 \\
\hline 19 & 60 & 70 & 124 & 3600 & 4900 & 15376 \\
\hline 20 & 58 & 65 & 119 & 3364 & 4225 & 14161 \\
\hline 21 & 62 & 65 & 118 & 3844 & 4225 & 13924 \\
\hline 22 & 63 & 70 & 124 & 3969 & 4900 & 15376 \\
\hline 23 & 63 & 70 & 119 & 3969 & 4900 & 14161 \\
\hline 24 & 64 & 60 & 118 & 4096 & 3600 & 13924 \\
\hline 25 & 61 & 60 & 124 & 3721 & 3600 & 115376 \\
\hline 26 & 63 & 65 & 119 & 3969 & 4225 & 14161 \\
\hline 27 & 54 & 70 & 118 & 2916 & 4900 & 13924 \\
\hline 28 & 60 & 65 & 124 & 3600 & 4225 & 15376 \\
\hline 29 & 57 & 65 & 119 & 3249 & 4225 & 14161 \\
\hline 30 & 60 & 70 & 118 & 3600 & 4900 & 13924 \\
\hline Jumlah & 1805 & 2010 & 3610 & 108839 & 135100 & 534610 \\
\hline
\end{tabular}


Kemudian data statistik terdapat adanya data yang realibel dari 15 item untuk 30 responden dengan hasil $80,1 \%$ antara peranan tenaga pengajar (dosen) profesional dalam pembentukan karakter mahasiswa untuk peningkatan kualitas pembelajaran.

Item Statistics

\begin{tabular}{|l|r|r|r|}
\hline & \multicolumn{1}{|c|}{ Mean } & \multicolumn{1}{c|}{$\begin{array}{c}\text { Std. } \\
\text { Deviation }\end{array}$} & $\mathrm{N}$ \\
\hline $\mathrm{b} 1$ & 4.3333 & .47946 & 30 \\
$\mathrm{~b} 2$ & 4.4333 & .50401 & 30 \\
$\mathrm{~b} 3$ & 4.6000 & .49827 & 30 \\
$\mathrm{~b} 4$ & 4.3667 & .49013 & 30 \\
$\mathrm{~b} 5$ & 4.4333 & .50401 & 30 \\
$\mathrm{~b} 6$ & 4.6000 & .49827 & 30 \\
$\mathrm{~b} 7$ & 4.3667 & .49013 & 30 \\
$\mathrm{~b} 8$ & 4.4333 & .50401 & 30 \\
$\mathrm{~b} 9$ & 4.6000 & .49827 & 30 \\
$\mathrm{~b} 10$ & 4.3667 & .49013 & 30 \\
$\mathrm{~b} 11$ & 4.4333 & .50401 & 30 \\
$\mathrm{~b} 12$ & 4.6000 & .49827 & 30 \\
$\mathrm{~b} 13$ & 4.3667 & .49013 & 30 \\
$\mathrm{~b} 14$ & 4.4333 & .50401 & 30 \\
$\mathrm{~b} 15$ & 4.6000 & .49827 & 30 \\
\hline
\end{tabular}

Item-Total Statistics

\begin{tabular}{|c|c|c|c|c|}
\hline & $\begin{array}{c}\text { Scale } \\
\text { Mean if } \\
\text { Item } \\
\text { Deleted }\end{array}$ & $\begin{array}{c}\text { Scale } \\
\text { Variance if } \\
\text { Item } \\
\text { Deleted }\end{array}$ & $\begin{array}{c}\text { Correct } \\
\text { ed } \\
\text { Item- } \\
\text { Total } \\
\text { Correla } \\
\text { tion }\end{array}$ & $\begin{array}{c}\text { Cronb } \\
\text { ach's } \\
\text { Alpha } \\
\text { if } \\
\text { Item } \\
\text { Delet } \\
\text { ed }\end{array}$ \\
\hline b1 & 62.6333 & 13.137 & .370 & .792 \\
\hline b2 & 62.5333 & 12.947 & .401 & .790 \\
\hline
\end{tabular}

\begin{tabular}{|l|l|l|l|l|} 
b3 & 62.3667 & 12.861 & .432 & .788 \\
b4 & 62.6000 & 13.007 & .398 & .790 \\
\hline b5 & 62.5333 & 12.947 & .401 & .790 \\
b6 & 62.3667 & 12.861 & .432 & .788 \\
b7 & 62.6000 & 13.007 & .398 & .790 \\
b8 & 62.5333 & 12.947 & .401 & .790 \\
b9 & 62.3667 & 12.861 & .432 & .788 \\
b10 & 62.6000 & 13.007 & .398 & .790 \\
b11 & 62.5333 & 12.947 & .401 & .790 \\
b12 & 62.3667 & 12.861 & .432 & .788 \\
b13 & 62.6000 & 13.007 & .398 & .790 \\
b14 & 62.5333 & 12.947 & .401 & .790 \\
b15 & 62.3667 & 12.861 & .432 & .788 \\
\hline
\end{tabular}

Selanjutnya untuk melihat uji hipotesis dari data X1 dengan $\mathrm{Y}$ maka dipergunakan uji korelasi dan regresi 2 person variabel. Hasil data $\mathrm{X} 1$ terhadap $\mathrm{Y}$ memiliki peranan yang signifikan antara tenaga pengajar profesional dengan kualitas pembelajaran dengan data korelasi $\mathrm{X} 1=5,75 \%$ terhadap data $\mathrm{Y}=0,01$ $\%$.

\section{a. $\mathrm{X} 1 \rightarrow \mathrm{Y}$}

\section{Correlations}

\begin{tabular}{|c|c|c|c|}
\hline \multicolumn{4}{|c|}{ Correlations } \\
\hline & & $\mathrm{x} 1$ & Y \\
\hline \multirow[t]{3}{*}{$\mathrm{x} 1$} & $\begin{array}{l}\text { Pearson } \\
\text { Correlation }\end{array}$ & 1 & $.575^{* *}$ \\
\hline & Sig. (2-tailed) & & .001 \\
\hline & $\mathrm{N}$ & 30 & 30 \\
\hline \multirow[t]{4}{*}{$\mathrm{y}$} & Pearson & $575^{* *}$ & 1 \\
\hline & Correlation & & \\
\hline & Sig. (2-tailed) & .001 & \\
\hline & N. & 30 & 30 \\
\hline
\end{tabular}




\begin{tabular}{|c|c|c|c|}
\hline \multicolumn{4}{|c|}{ Correlations } \\
\hline & & $\mathrm{x} 1$ & $\mathrm{Y}$ \\
\hline \multirow[t]{3}{*}{$\mathrm{x} 1$} & $\begin{array}{l}\text { Pearson } \\
\text { Correlation }\end{array}$ & 1 & $.575^{* *}$ \\
\hline & Sig. (2-tailed) & & .001 \\
\hline & $\mathrm{N}$ & 30 & 30 \\
\hline \multirow[t]{4}{*}{$\mathrm{y}$} & Pearson & $575^{\text {*** }}$ & 1 \\
\hline & Correlation & & \\
\hline & Sig. (2-tailed) & .001 & \\
\hline & $\mathrm{N}$. & 30 & 30 \\
\hline
\end{tabular}

**. Correlation is significant at the 0.01 level (2-tailed).

b. $\mathrm{X} 2 \rightarrow \mathrm{Y}$

80

Correlations

\begin{tabular}{|r|r|r|}
\multicolumn{3}{|c|}{ Correlations } \\
\hline & \multicolumn{1}{|c|}{$\mathrm{y}$} & \multicolumn{1}{|c|}{$\mathrm{x} 2$} \\
\hline $\mathrm{y} \quad \begin{array}{l}\text { Pearson } \\
\text { Correlation } \\
\text { Sig. (2- } \\
\text { tailed) } \\
\mathrm{N}\end{array}$ & 1 & $.735^{* *}$ \\
\hline $\mathrm{x} 2 \begin{array}{l}\text { Pearson } \\
\text { Correlation }\end{array}$ & $.735^{* *}$ & \\
\hline $\begin{array}{l}\text { Sig. (2- } \\
\text { tailed) } \\
\mathrm{N}\end{array}$ & .000 \\
\hline
\end{tabular}

**. Correlation is significant at the 0.01 level (2-tailed).

Selanjutnya data korelasi X2 terhadap $\mathrm{Y}$ memiliki data yang signifikan dan valid antara variabel X2 dan variabel Y. Data tersebut memiliki peranan 0,735 pembentukan karakter mahasiswa terhadap kualitas pembelajaran 0,1 $\%$. c. $\mathrm{X} 1, \mathrm{X} 2 \rightarrow \mathrm{Y}$

\section{Regression}

Variables Entered/Removed ${ }^{\mathrm{b}}$

\begin{tabular}{|l|l|l|l|}
\hline Model & \multicolumn{1}{|c|}{$\begin{array}{c}\text { Variables } \\
\text { Entered }\end{array}$} & $\begin{array}{c}\text { Variables } \\
\text { Removed }\end{array}$ & \multicolumn{1}{|c|}{ Method } \\
\hline 1 & $\mathrm{x} 2, \mathrm{x} 1^{\mathrm{a}}$ & & Enter \\
\hline
\end{tabular}

a. All requested variables entered.

b. Dependent Variable: y

Kemudian dicari data analisis regresi linear 2 prediktor antara $\mathrm{X} 1, \mathrm{X} 2$ dan $\mathrm{Y}$. Hasil datanya adalah $0,737 \%$ dengan $0,543 \%$. Dimana memiliki peranan yang signifikan dan valid antara tenaga pengajar profesional dalam pembentukan karakter mahasiswa untuk peningkatan kualitas pembelajaran diprodi pendidikan luar sekolah fakultas ilmu pendidikan universitas negeri medan. 
Model Summary

\begin{tabular}{|c|c|c|c|c|c|c|c|c|c|}
\hline \multirow[b]{2}{*}{ Model } & \multirow[b]{2}{*}{$\mathrm{R}$} & \multirow[b]{2}{*}{ R Square } & \multirow[b]{2}{*}{$\begin{array}{l}\text { Adjusted R } \\
\text { Square }\end{array}$} & \multirow[b]{2}{*}{$\begin{array}{l}\text { Std. Error of } \\
\text { the Estimate }\end{array}$} & \multicolumn{5}{|c|}{ Change Statistics } \\
\hline & & & & & $\begin{array}{l}\text { R Square } \\
\text { Change }\end{array}$ & F Change & df1 & df2 & $\begin{array}{c}\text { Sig. F } \\
\text { Change }\end{array}$ \\
\hline 1 & $.737^{\mathrm{a}}$ & .543 & .509 & 4.99343 & .543 & 16.037 & 2 & 27 & .000 \\
\hline
\end{tabular}

a. Predictors: (Constant), $\mathrm{x} 2, \mathrm{x} 1$

Selanjutnya data di atas dalam penelitian ini juga dapat di cara dengan menggunakan regresi linier dua predictor yang mana hasilnya adalah R : 0,737 > R Square 0,543 yang memiliki standar error 0,499 . peranan seorang tenaga pengajar (dosen) professional dalam pembentukan karakter mahasiswa untuk peningkatan kualitas pembelajaran di prodi PLS, maka dapat diambil suatu simpulan sebagai berikut :

1. Terdapat adanya data yang reabel

ANOVA $^{b}$

\begin{tabular}{|ll|r|r|r|r|r|}
\hline Model & Sum of Squares & Df & Mean Square & F & Sig. \\
\hline 1 & Regression & 799.741 & 2 & 399.870 & 16.037 & $.000^{\mathrm{a}}$ \\
& Residual & 673.226 & 27 & 24.934 & \\
\hline Total & 1472.967 & 29 & & & \\
\hline
\end{tabular}

a. Predictors: (Constant), $\mathrm{x} 2, \mathrm{x} 1$

b. Dependent Variable: y

\section{KESIMPULAN}

\section{Simpulan}

Berdasarkan hasil dari

observasi dan test selama penelitian baik itu di test awal dalam proses pembelajaran dan di test akhir proses pembelajaran yang dilakukan oleh masing-masing tenaga pengajar (dosen) di prodi PLS maka ditemukan untuk mengukur seberapa dari 15 item untuk 30 responden dengan hasil 80,1\% antara peranan tenaga pengajar (dosen) profesional dalam pembentukan karakter mahasiswa untuk peningkatan kualitas pembelajaran.

2. Untuk melihat uji hipotesis dari data X1 dengan Y maka dipergunakan uji korelasi dan regresi 2 person variabel. Hasil data X1 terhadap Y memiliki peranan yang signifikan antara tenaga pengajar profesional dengan kualitas pembelajaran dengan 
data korelasi $\mathrm{X} 1=5,75 \%$ terhadap data $\mathrm{Y}=0,01 \%$.

3. Data korelasi X2 terhadap $\mathrm{Y}$ memiliki data yang signifikan dan valid antara variabel X2 dan variabel Y. Data tersebut memiliki peranan7,35\% pembentukan karakter mahasiswa terhadap kualitas pembelajaran $0,1 \%$.

4. Data analisis regresi linear 2 prediktor antara X1,X2 dan Y. Hasil datanya adalah $0,737 \%$ dengan 0,543\%. Dimana memiliki peranan yang signifikan dan valid antara tenaga pengajar profesional dalam pembentukan karakter mahasiswa untuk peningkatan kualitas pembelajaran diprodi pendidikan luar sekolah fakultas ilmupendidikan universitas negeri medan.

\section{Saran}

Adapun yang menjadi saran dalam penelitian ini adalah sebagai berikut :

1. Bagi tenaga pengajar diharapkan untuk meningkatkan lagi kualitas pembelajarannya bagi mahasiswa.

2. Bagi mahasiswa untuk dapat meningkatkan kualitas pembelajarannya.

3. Bagi peneliti yang lain agar dapat melanjutkan penelitian selanjutnyasecara baik dan akurat.

\section{DAFTAR PUSTAKA}

Baihaqie, N. 2000. Peran Guru dalam Perubahan Tata Nilai pada Era Transformasi. Jurnal Kependidikan Media
Publikasi Ilmiah, No. 2, Th.

1.

Brodjonegoro, S.S. 2002. Perguruan Tinggi Sebagai Kekuatan Moral. Disampaikan dalam Rapat Kerja Nasional Pimpinan Perguruan Tinggi Negeri Seluruh Indonesia, Yogyakarta.

Budimansyah, D. 2002. Model Pembelajaran dan Penilaian Berbasis Portofolio. Bandung: Genesindo.

Dunkin, M.J. dan Biddle, B.J. 1974. The Study of Teching. New York: Holt, Rinehart Company.

Depdiknas. 2002. Standar Kompetensi Guru Kelas SDMI, Program Pendidikan D II PGSD. Jakarta: Depdiknas.

Depdiknas, Biro Hukum dan Organisasi. 2003. Warta Hukum dan Perundangundangan, Vol 4, No. 2.

Direktorat Penelitian dan Pengabdian pada Masyarakat. 2002. Kebijakan dan Program Penelitian dan Pengabdian kepada Masyarakat. Jakarta: Departemen Pendidikan Nasional

Djamarah, S.B. 2000. Guru dan Anak Didik dalam Interaksi 
Edukatif. Jakarta: Rineka Cipta.

Effendi, S. 2003. Pengelolaan Perguruan Tinggi Menghadapi Tantangan Global. Disampaikan dalam Seminar Nasional Majelis Rektor Indonesia, Makassar.

Grossman, P. 1991. Mapping the terrain: Knowledge Growth in Teaching. Dalam Waxman, H.C. dan Walberg, H.J. (Ed.), Effective Teaching: Current Research. Berkeley: McCutchan Publishing Corporation.

Guntur, Y.S., Soepomo, B., dan Gitoyo. 2002. Analisis Pengaruh Pengalaman terhadap Profesionalisme dan Analisis Pengaruh Profesionalisme terhadap Hasil Kerja (Outcomes). Maksi, Vol. 1.

Kemp, J.E. 1994. Proses Perancangan Pengajaran (terjemahan). Bandung: ITB.

Mahmud, A. 2002. Performansi dan Motivasi Dosen Ditinjau dari Gaya Pimpinan PTS di Propinsi NTB. Jurnal Kependidikan Media Komunikasi Ilmiah, No. 2, Th. 1 .
Nunan, D. 1991. Language Teaching Methodology, A text book for teacher. New York: Prentice Hall.

Richards, J.C. dan Rodgers, T.S. 1986. Approaches and Methods in Language Teaching, A Description and Analysis. Cambridge: Cambridge University Press. Semiawan, C.R. 1998. Pendidikan Tinggi Peningkatan Kemampuan Manusia Sepanjang Hayat Seoptimal Mungkin. Jakarta: Depdikbud.

Soedijarto. 1991. Sebuah Pemikiran tentang Kurikulum yang Relevan untuk Menunjang Pembangunaan Menuju Tinggal Landas. Dalam Semiawan, C.R. dan Soedijarto (Ed.), Mencari Strategi Pengembangan Pendidikan Nasional Menjelang Abad XXI. Jakarta: Grasindo.

Tadjudin, M.K. 2002. Sistem Penjaminan Mutu Internal Perguruan Tinggi: Aplikasinya di UI. Disampaikan pada Rapat kerja nasional Pimpinan Perguruan Tinggi Seluruh Indonesia, Yogyakarta. 
